\title{
INCREASE EFFICIENCY OF BRAKING ENERGY IN METRO
}

\author{
Elena M. Shabanova \\ Novosibirsk State Technical University \\ Novosibirsk, Russia \\ Baranova_E_M@mail.ru
}

\author{
Valeriy V. Biryukov \\ Novosibirsk State Technical University \\ Novosibirsk, Russia \\ vavib49@mail.ru
}

\begin{abstract}
One of the most topical problems of the electric power industry in the transport sector is the problem of improving the energy efficiency of vehicles and the transport system as a whole. Electric traction is a significant share in the overall structure of consumption of urban electric transport, and the amount of electricity consumed by traction is constantly growing. One of the main reserves that make it possible to reduce the consumption of electricity by traction substations from the primary grid is the use of regenerative braking on the electric rolling stock. The question of the most expedient application of the energy of regenerative inhibition remains open. The ways of secondary use of electric energy received as a result of recuperative braking of the rolling stock of electric transport are analyzed.
\end{abstract}

Keywords - energy recuperation, urban electric transport, technical solutions, electricity consumed.

\section{INTRODUCTION}

One of the main tasks of the energy sector has been and remains the task of rational use of existing resources. As the statistics show, the energy consumption of large industrial regions, such as the Novosibirsk region, is steadily increasing year by year, and today it is more than 1500 million $\mathrm{kW} \cdot \mathrm{h}$ [1]. The most energy-intensive consumers of the region include industrial enterprises, agro-livestock complexes, and city electric transport enterprises (CET). In the first and second cases, the reduction of electrical energy consumption, as a rule, can be achieved by optimizing the technological processes. The issue of energy saving at the CET is more specific and its solution requires a whole range of measures, not only local but also state level.

One of them is the equipping of city electric transport with energy-efficient equipment, which is a priority area of the Novosibirsk Region State Program "Energy Saving and Improving Energy Efficiency in the Novosibirsk Region for 2015-2020". Thus, the use of asynchronous traction motors (ATM) on electric rolling stock (ERS) makes it possible to significantly improve the performance of power electrical equipment, to optimize the mass-dimensions of the traction drive. In addition, the costs for repair and maintenance of such electric motors are substantially reduced. In the nominal operating mode, with a good form of the output voltage of the autonomous inverter, the asynchronous traction motor has a higher efficiency value compared to the collector [2]. The ATM control system based on power semiconductor devices allows for smooth regenerative braking in a wide range of speeds without special exciters or windings of parallel excitation of the traction motor [3].

\section{THEORY}

The active application of recuperative braking on city electric transport represents the most effective possibility of obtaining energy savings in sizes from 15 to $30 \%$ of the total energy consumption for traction. To date, the possibility of recovery is far from being fully utilized. The main reason for this is a certain complication of the electrical equipment of the rolling stock and its operating modes [4]. In addition, the possibility of recovery is substantially limited by two conditions: the need to maintain a high speed of movement, in which the EMF of the traction motor is higher than the mains voltage, and the consumer of the generated energy on the common section of the traction network, if it is impossible to accumulate it or transfer it to an external network. The use of pulse control circuits allowed to increase the voltage generated by the motor, which expanded the range of speeds in which energy recovery is possible. At the same time, the problem of the lack of an energy recovery receiver has not yet been unambiguously resolved [5].

The electric power generated by traction motors, which operate in regenerative braking in the generator mode, can be utilized as follows:

- stocked in accumulation elements installed on the rolling stock;

- transferred to storage elements installed on a traction substation or at different sections of the cable network;

- transferred to another rolling stock, which is nearby and works in traction mode;

- transferred to the nearest traction substation (without a drive), on which an inverter converter is installed, which transfers energy to the primary supply network.

The implementation of the first option involves equipping the rolling stock with an energy storage device (ES). This technical solution, in turn, allows you to align the load schedule, improve the voltage quality at the current collectors, reduce the installed capacity of the step-down and converter transformers of traction substations, reduce power losses in the traction network, increase the life of current-carrying elements of the contact network and power semiconductor units. The method for calculating the energy intensity of a storage device 
TABle I. COMPARATIVE ANALYSIS OF ENERGY STORAGE

\begin{tabular}{|l|c|c|c|}
\hline \multirow{2}{*}{ Parameter } & \multicolumn{2}{|c|}{ System } \\
\cline { 2 - 4 } & Accumulator & \multicolumn{2}{|c|}{ Supercapacitor } \\
\hline Efficiency, \% & 70 & 95 \\
\hline Energy intensity, $\mathrm{kW} \cdot \mathrm{h} / \mathrm{kg}$ & 150 & 15 & $10^{6}$ \\
\hline The number of cycles & $10^{3}$ & 10 & 30 \\
\hline Life cycle, years & $3-5$ & sec & high \\
\hline Charge time & $\mathrm{h}$ & 200 \\
\hline Output power & mean & mean & min \\
\hline Cost & low & low \\
\hline Ecological problems & mean & high & \\
\hline
\end{tabular}

placed directly on the rolling stock is described in [6], and methods for increasing the energy efficiency of regenerative braking with this method of locating ES are described in [7].

Such developments exist, but the use of the energy storage on board implies an increase to $1 \ldots 2 \%$ of the energy consumption for traffic due to the increase in the mass of the rolling stock, and on some vehicles - the reduction in the payload (the number of passengers or cargo) that the rolling stock can take. As practice shows, such upgrades on operated subway cars can not always be agreed with the manufacturer.

In addition, the question arises of the choice of the type of energy storage devices, which is due to a wide range of their energy and mass-dimensional parameters. At the same time, a number of requirements are imposed on storage devices for accumulating electric braking energy, placed both permanently and on a vehicle. The main ones are the following:

- high specific energy indicators;

- Acceptable weight and size indicators (especially for vehicles placed on the rolling stock);

- the required number of charge-discharge cycles;

- maintainability without deteriorating performance in a wide temperature range [8].

According to the data of [9], the ratio of the main parameters of energy storage units looks as follows (see Table $1)$.

In electric power supply systems of urban electric transport, electromechanical, capacitive and superconducting inductive energy storage devices were used.

To use energy storage for the purpose of storing and delivering the energy of recovery at the right time when braking trains, two types are most suitable: flywheels and supercapacitors.

In addition to the direct effect on saving energy consumption, the drives have a beneficial effect on the electricity supply systems of subways.

In order to minimize energy losses during transportation on board massive storage devices and to maintain the massdimension parameters of the rolling stock, the vast majority of pilot projects in subways are oriented to the stationary application of storage devices.
The economic efficiency of the use of energy storage devices in power supply systems of subways reaches $40 \%$, and the efficiency of flywheel drives is much higher than supercapacitors.

The specific value for the subways is the unit cost of the installed kilowatt capacity. The price of one kilowatt of power for supercapacitors exceeds the various types of flywheels from 1.5 to 5 times.

Supercapacitors and inertial storage devices have high specific power, can be operated in peak and boosted modes in a wide temperature range from minus $65^{\circ} \mathrm{C}$ to plus $70^{\circ} \mathrm{C}$, but their specific energy content is lower than that of electrochemical storage batteries.

Electrochemical energy storage devices in long discharge modes have a high specific energy intensity and high efficiency, but in peak and forced modes, as well as at temperatures below $15^{\circ} \mathrm{C}$ and above $45^{\circ} \mathrm{C}$, their efficiency decreases.

The most appropriate now is the application in the traction power supply system of energy storage devices of two types capacitive (supercapacitor) and electrochemical (battery), due to a number of characteristics, or created on their basis of a hybrid storage [10].

The use of energy storage in the power supply system (in the traction substation, in inter-substation zones) is not always justified in terms of economic indicators.

There are four options for allocating storage devices:

- on the traction substation;

- on the terminals of the supply lines;

- in the inter-station zone;

- along the contact network.

The choice of placement primarily depends on the economic efficiency and ease of use; In addition, losses of electrical energy, which are associated with a specific specificity of electricity transmission, are taken into account.

When recovering, the most economical mode is such that all the energy generated by the electric rolling stock is transferred to the nearby energy storage device, and at the time of the energy accumulator discharge, the nearest rolling stock working in traction mode. According to this principle, the 
most rational from the point of view of loss reduction will be the placement of the drive at the stopping point, since the braking and thrust modes last longer here.

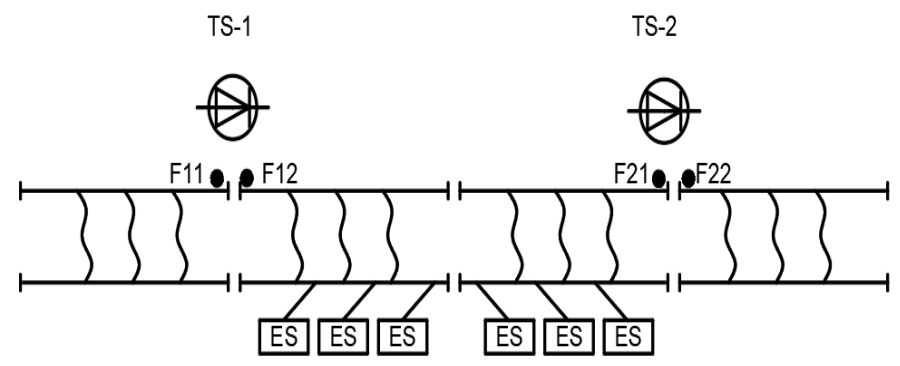

Fig. 1. The variant of energy storage along the contact network

The existing power and partitioning schemes within a single feeder section usually have three stopping points, so the number of energy storage devices (with distributed power) in one section must be at least three. This will lead to a sharp increase in capital and operating costs, and the savings in electrical energy due to the introduction of drives will be less than the operational costs.

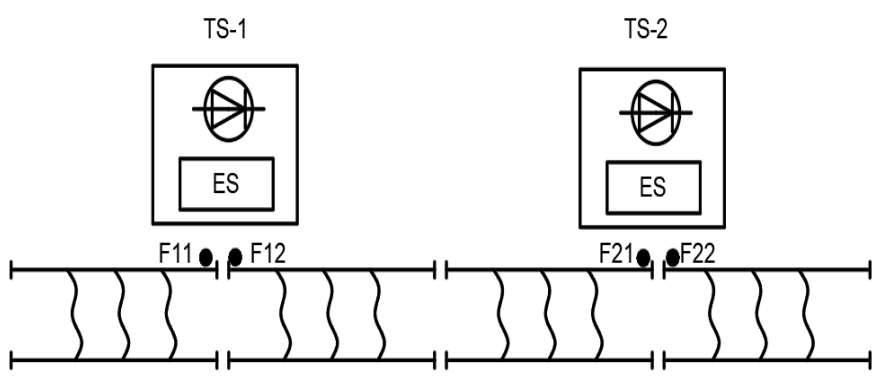

Fig. 2. The variant of energy storage - on the traction substations

From the point of view of serviceability, the optimal location for the energy storage is a traction substation where equipment has already been installed that allows for shutdowns in emergency operation modes of both traction power supply system and the energy storage device itself. The solution of this problem is described also in [11]. Additional advantages of placing the energy accumulator on the traction substation is the constancy of the temperature, which allows to increase the life of the drive. At the same time, an energy store designed with a sufficiently large specific energy reserve will allow accumulating excess energy of several feeder zones. Depending on the traffic intensity, one energy store installed on the traction substation can serve from 2 to 4 feeders. When determining the number of served feeders by one energy storage device, it is necessary that the discharge time should be less than the charge time. Otherwise, the drive will not be able to charge and there will be no significant improvement in the operating mode of the power supply system. The main disadvantages of this arrangement of the energy storage device are the large losses associated with energy transfer and the inability to perform regenerative acts when the electric rolling stock is removed from the feeder feeder.

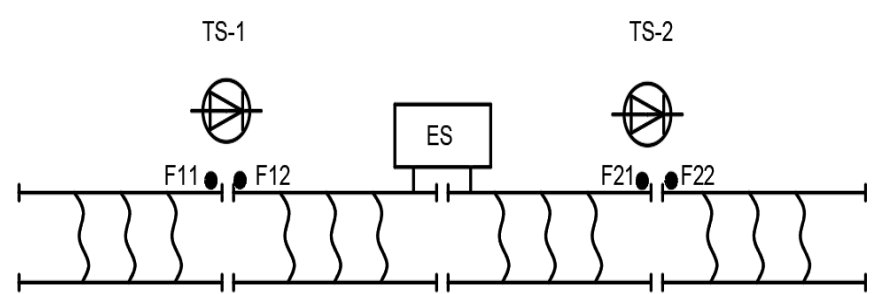

Fig. 3. The variant of energy storage in the interfeeder zone

The introduction of energy storage in the inter-substation zone is the most rational option. With this allocation method, capital costs due to the installation of one storage element in two sections are significantly lower than when energy storage devices are placed at stopping points, where six energy storage devices with current and voltage monitoring systems of charge-discharge processes are required [12].

The least expensive way to use energy recovery is intertrain exchange - an option for the use of regenerative braking, which consume the generated electric power of the train, operating at this time in the traction mode. Electricity savings in the application of regenerative braking on metro trains can be $5-25 \%$, and at some distances about $30-40 \%$ [13]. As the studies [14] show, the coincidence of acts of starting and braking of rolling stock on the line during peak hours has a probabilistic character and does not exceed 35\%. This method of energy use is essentially limited to the path profile: the most efficient energy use occurs on long slopes when the energy source moves in the braking mode on the descent and the receiver in the traction mode on the rise; and the intensity of motion on the stretch: with a greater traffic intensity, the probability of using energy is greater.

The last way to use energy recovery is considered extremely rare, but there are successful projects to implement it. So, Mitsubishi Electric in 2011 developed inverters based on silicon carbide $(\mathrm{SiC})$ for use in railway rolling stock. And since 2014, the S-EIV station power-saving inverter is being used at the Tokyo metro station "Mioden", daily saves are about $600 \mathrm{~kW} \cdot \mathrm{h}$, which is enough to provide electricity for about 60 homes. The electric power produced as a result of the operation of the regenerative braking systems is directed to feed the trains on neighboring lines, but not all of this is spent, some are directed to the lighting of stations, the operation of air conditioning and escalators. The S-EIV system directly feeds the station with the electricity saved in this way. S-EIV does not use storage devices, but directly converts electric current to alternating current, excluding the deterioration of the quality of electricity in the station network [15].

In addition, in January 2018, Mitsubishi Electric introduced a new energy-saving station inverter (Station Energy Saving Inverter - S-EIV) with an output voltage of 400 V AC. Unlike systems with an output voltage of $200 \mathrm{~V} \mathrm{AC,}$ new systems can be installed in the distribution circuits of stations with powerful, particularly responsible consumers, reducing the voltage drop and losses in electrical networks for efficient supply of elevators or escalators. Due to the compatibility with $400 \mathrm{~V}$ AC networks, the new model allows one to abandon the step-up transformers. 
The use of energy recovery through inverting well established itself in the London metro. The electricity storage system installed at the Claudesley Road substation of the Victoria Line of the London Underground allowed to supply electricity to a large Holborn station for two days a week [16].

Currently, inverter converters are developed on the basis of bipolar transistors with isolated gate (IGBT) and pulse width However, the use of inverters has a number of limitations:

- when transferring the recovered electric power from the electric rolling stock to the traction substation inverters and then to the primary power transmission line, energy losses amounting to $5 \%$ of the total energy of the recovery are generated;

- the use of inverters leads to an accelerated aging of the contact wire due to the flow of additional excess regeneration currents, which, in addition, reduce the throughput of the contact network according to the heating conditions;

- inverter converters have a low power factor $\lambda$, so that the value of $\lambda$ of the traction substation in the inverting mode is no more than 0.6. Due to non-linearity of the source of recuperation, the recovered electricity transferred to the external power system is low-quality energy, which means that it has a low cost and thus does not justify not only the capital, but also operating costs for the implementation of the regenerative braking regime [7].

Therefore, an important task in the study of recovery issues is the task of improving the quality of electric braking.

\section{EXPERIMENTAL RESULTS}

The use of inverter converters in traction substations of city electric transport with the purpose of supplying the system of own needs with electricity, recovering trains, is one of the most promising directions of using secondary electric power in the transport complex.

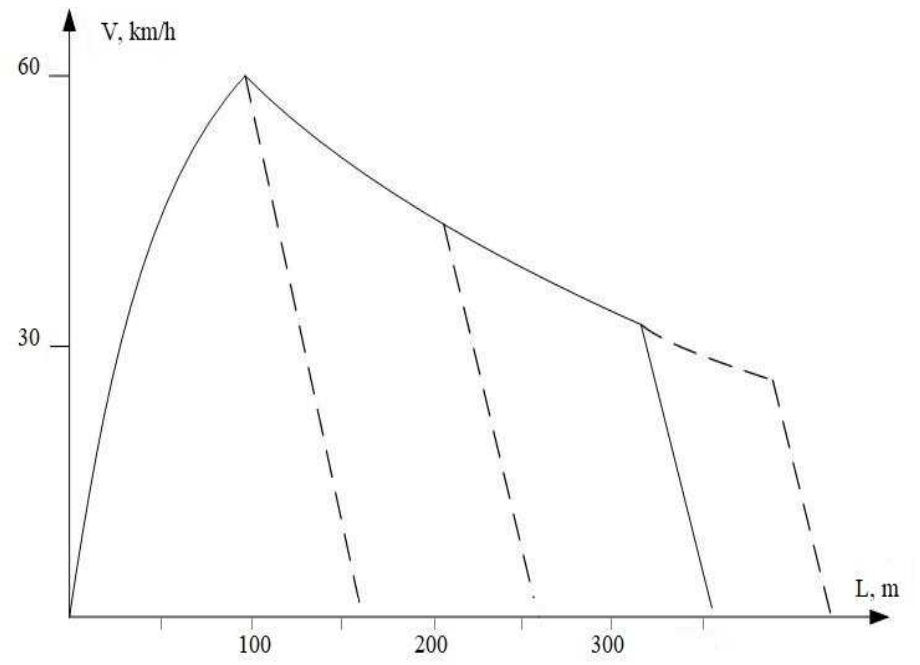

Fig. 4. Movement curves

The analysis of the modes of movement of the electric rolling stock shows a significant difference in comparison with the driving regimes, both vehicles with thermal engines, and between such types as trams, trolleybuses, subways, electric commuter trains, etc. The process of energy consumption for electric vehicles is discrete. When moving such modes of transport as a tram and trolley bus, the movement is carried out according to the classical scheme "start-run-stop-braking". Depending on the length of the distillation, the curves of the realization of such a circuit as a function of the length of the distillation are of the character shown in Fig. 4 [17].

With regard to the rolling stock of the subway, electric commuter trains, locomotives of railway transport, depending on the length of the distillation, the traffic pattern undergoes a change from the classical to the scheme of road transport, when the second component decreases, and then disappears. As calculations show, for urban land transport the ratio of energy consumed and recovered is as follows (Fig. 5).

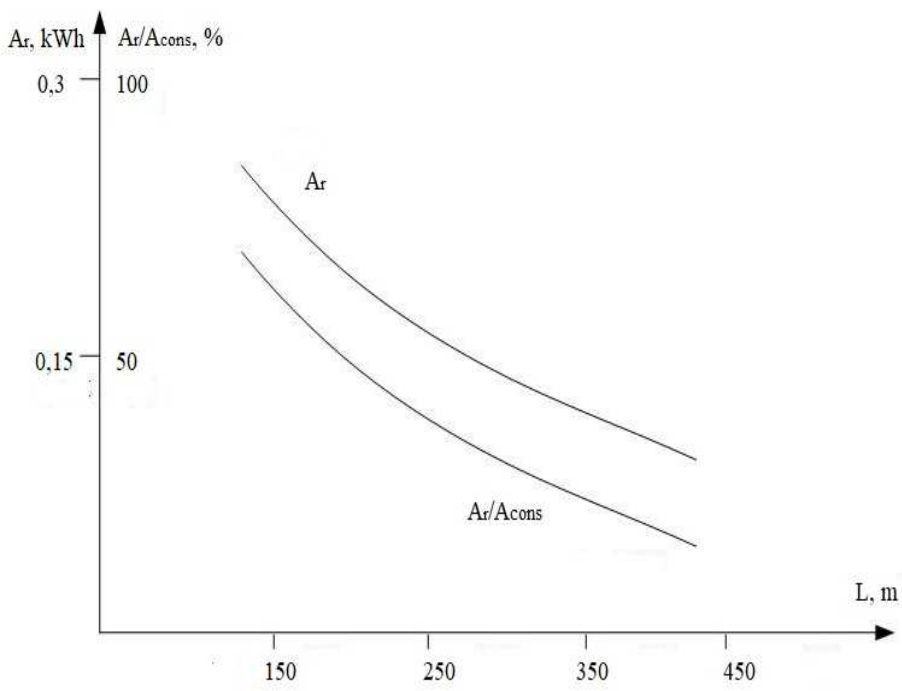

Fig. 5. Energy consumption curves as a function of the length of the distillation

Reducing energy consumption during the movement of the classical scheme can be achieved in the following ways:

- optimization of driving regimes of electric rolling stock, due to professional retraining of drivers;

- using a traction drive based on power semiconductor technology;

- conservation of energy recovery through the accumulation of it and transformation to the form necessary for secondary use by consumers, both the electric transport complex and others.

For trams and trolley buses, whose movement occurs on comparatively short distances, energy recovery is possible, both in the storage tanks located in the traction network and on the rolling stock. In this case, there is no need to convert the type of current.

Unlike the trams and trolleybuses on the subway, energy consumption for the needs of traction is about $40 \%$ of all consumed electricity. The main energy consumers are auxiliary equipment, which include escalator drives, 
ventilation systems, lighting, etc. And their consumption of energy occurs in contrast to the supply of electric trains of traction networks with alternating current, and continuously. This state of affairs assumes one more way of realization of energy of regenerative braking - inverting for the purpose of supplying auxiliary equipment.

On average, electric power consumption in $220 \mathrm{~V}, 380 \mathrm{~V}$ AC networks can be represented by the following percentage: $3 \%$ ventilation systems, $17 \%$ escalator drives, $18 \%$ other consumers, $62 \%$ lighting of traction substations, vestibules, platforms, tunnels and others.

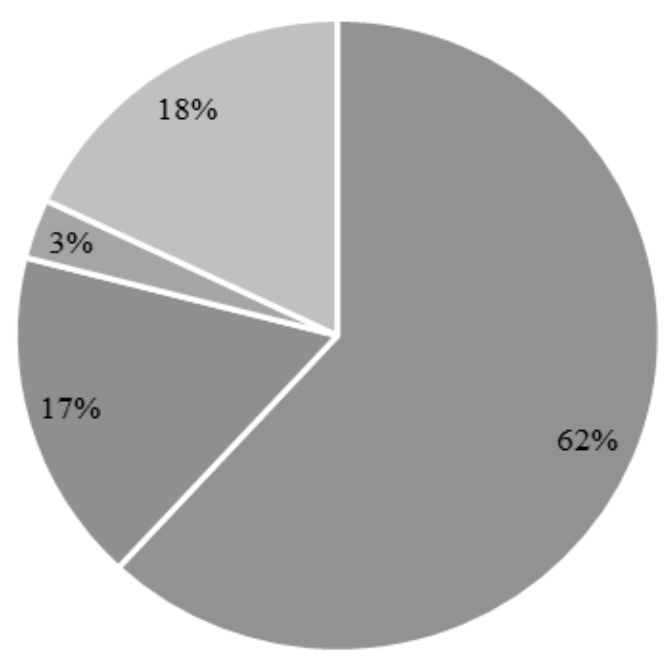

Fig. 6. Power consumption in networks $220 \mathrm{~V}, 380 \mathrm{~V}$

The auxiliary equipment of devices consuming electric energy operates in various modes, including long-term ones, which eliminates the problem of finding a consumer of recovered energy, given only during the braking of the vehicle. In addition, the presence of a constant consumer allows to reduce to a minimum the capacity of the accumulator of the recovered energy, which ensures only stable operation of the inverter.

\section{CONCLUSIONS}

Further research in this direction will make it possible to clarify the proposed provisions and justify the decisions taken.

Based on the above, it can be concluded that inverting for the purpose of feeding auxiliary equipment is the most appropriate option for using the energy of recovery in the subway. To determine the possibility of power supply for the subway's own needs systems, inverted recovery current, it is necessary to perform a harmonic analysis of the regeneration current, determine the power of the required energy storage device, and also the variant of its placement, to develop a circuit solution for the inverter, which determines the further direction of the research.

[1] Electricity consumption in the United Energy System of Siberia for March 2018 increased by 3.7\% compared to March 2017 [Electronic resource]. - URL: https: //so-cdu.ru/index.php

[2] N. A. Rotanov, A. S. Kurbasov, Yu. G. Bykov, V. V. Litovchenko; Ed. N. A. Rotanovs, Electroconv. Composition with asynchronous traction engines. M.: Transport, 1991.

[3] V. E. Rozenfel'd, V. V. Shevchenko, Thyristor control of electric rolling stock of direct current, M.: Transport, 1970.

[4] V. G. Ulitin, "Problems of using excess energy recovery on urban electric transport", Scientific and technical collection "Municipal economy of cities", Kharkov, Vol. 88, pp. 266 - 270, 2009.

[5] M. V. Yaroslavtsev, Energy-efficient traction drive of urban trackless transport: Thesis for the degree of Candidate of Technical Sciences, Novosibirsk, 2016.

[6] G. G. Ryabtsev, I. A. Ermakov, N. A. Rubichev, "Calculation of capacitor energy storage for underground cars", Electrical Engineering, Vol. 8, pp. 15 - 19, 2011.

[7] N. A. Kostin, A. V. Nikitenko, "Autonomy of recuperative braking is the basis of reliable and energy-efficient recuperation on the electric rolling stock of direct current", Zaliznichny transport of Ukraine, Kiev, Vol. 3, pp. $15-22,2014$.

[8] E. A. Spiridonov. Increase of energy efficiency in electric transport complexes with storage devices: Thesis for the degree of candidate of technical sciences, Novosibirsk, 2010.

[9] M. A. Sokolov, V. S. Tomasov, R. P. Jastrzębski, "Comparative Analysis of Energy Storage Systems and Determination of Optimal Applications of Modern Super Machines", Scientific and Technical Herald of Information Technologies, Mechanics and Optics. St. Petersburg, Vol. 4, pp. 149 - 155, 2014.

[10] M. O. Musabekov, "Innovative way of using energy recuperation", Materials of the XLI International Scientific and Practical Conference KazATK them. M. Tynyshpayev, vol. 3, pp. 162 - 166, April 2017 [Innovative technologies in transport: education, science, practice, p. 545, 2017].

[11] K. V. Shcheglov, A. A. Shtang, N. I. Shchurov, "Application of energy storage devices in electric traction systems", Collected scientific papers of the NSTU, Novosibirsk: Publishing House of the National Technical University, Vol. 1 (51), pp. 99 - 104, 2008.

[12] A. A. Shtang, E. A. Spiridonov, M. V. Yaroslavtsev, "Application of energy storage devices in electric power supply systems of urban electric transport", Transport of the Russian Federation, Vol. 3 - 4, pp. 68 - 70, 2012 .

[13] A. A. Sulim, S. D. Sichev, V. R. Raspopin, "Electricity savings by using recuperative braking on subway cars", mater. X Int. nauch.-teh. Conf. Electromechanical and Energy Systems, Methods of Modeling and Optimization, p. 344, 2012.

[14] K. I. Kulikov, E. A. Spiridonov, K. E. Ponomarev, E. G. Langeman, "Traffic interval influence for the probability of inter-train recovery energy exchange in metropolitan", Proceedings of the Russian higher school Academy of sciences, Vol. 2 (35), pp. 53-60, 2017.

[15] Mitsubishi Electric, "S-EIV® Mitsubishi Electric System Reduces Electricity Consumption in the Tokyo Metro", International Scientific Journal Alternative Energy and Ecology, Publisher: Scientific and Technical Center "TATA" (Sarov), Vol. 20, pp. 156, 2014.

[16] The British learned to save the braking energy of trains [Electronic resource]. - URL: https://nplus1.ru/news/2015/09/28/recuperation.

[17] V. E. Rozenfeld, I. P. Isaev, N. N. Sidorov, M. I. Ozerov; Ed. I. P. Isayeva, Theory of electric traction, Moscow: Transport, 1995. 